\title{
Bioactive peptides from beef products fermented by acid whey - in vitro and in
}

\section{silico study}

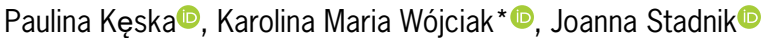

University of Life Sciences in Lublin - Dept. of Animal Raw Materials and Technology, Skromna 8 - 20-704 - Lublin Poland.

*Corresponding author <karolina.wojciak@up.lublin.pl>

Edited by: Pedro Esteves Duarte Augusto

Received January 03, 2018

Accepted April 13, 2018

\begin{abstract}
This research investigated the potential of beef products with acid whey to release bioactive peptides and thereby emphasize their health-promoting potential. Peptide sequences were isolated and identified by liquid chromatography-electrospray ionization-mass spectrometry (LC-ESI-MS). Firstly, the antihealth properties (toxicity, allergenicity) of the peptides were estimated based on the peptide sequences. Next, their health-promoting potential was demonstrated based on an in silico analysis by determining their bioactivity scores (PeptideRanker). Their various biological actions were also determined using BIOPEP-UWM tools. We presented peptide sequences with properties relevant to ensuring good health and well-being, including cardiovascular system, nervous and immune systems, or their support for the maintenance of general homeostasis. We obtained information on generation of biologically active peptides in uncured beef with acid whey and it can be considered as a new knowledge as it contributes to science development of functional and nutraceutical foods. In the long term, this information can be used in designing products with desired nutritional and health-promoting properties that are important for the well-being and for preventing the occurrence of noncommunicable diseases.

Keywords: biological active peptides, allergenity, uncured beef, healthy meat product
\end{abstract}

\section{Introduction}

Action mechanisms of biologically active peptides derived from meat and meat products are described in the literature (Ha and Zemel, 2003; Lafarga and Hayes, 2014). However, the search for new food sources of biologically active peptides is the current trend in food science. Fermented beef marinated in acid whey could be such kind of product. The available literature provides a detailed account on the biological activity of specific whey components, including whey proteins and peptides as well as amino acids (Tavares and Malcata, 2013). Most experiments confirming bioactivity of whey proteins were conducted in vitro and in vivo (Pihlanto-Leppälä, 2000; Lasik et al., 2011; Zhou et al., 2017; Le Maux et al., 2018). Biologically active substances with high health potential in acid whey include immunoglobulin A, $\beta$-lactoglobulin, $\alpha$-lactoglobulin, glutamine, lactoferrin, lactoferricine, lisozyme, and glutathione. A previous study reported that the use of acid whey as replacement of sodium nitrite in the manufacturing of meat products inhibits the growth of undesirable microflora, creates a pink-color and has significant impact on the sensory profile of products acceptable by consumers (Wójciak and Dolatowski, 2015; Wójciak et al., 2015; Wójciak and Solska, 2016). During meat fermentation, acid whey contributes not only to meat tenderness, but also to generation of peptide fractions in products, which may cause significant physiological effect in human body, such as antioxidant and blood pressure lowering effects, at least in vitro (unpublished data). Interaction of meat proteolytic factors with those delivered with whey can result in the formation of specific sequences. The delivery of biologically active ingredients, such as peptides, can modu- late or activate endogenous regulatory mechanisms in the human body thereby limiting the occurrence of lifestyle diseases (Garcia et al., 2017; Martínez-Sánchez et al., 2017; Montoro-García et al., 2017). Therefore, this research was conducted to investigate the capabilities of beef products with acid whey to release the bioactive peptides after ripening and one month of storage at $4{ }^{\circ} \mathrm{C}$ and thereby to emphasize the health-promoting potential of these meat products.

\section{Materials and Methods}

\section{Sample preparation}

Semimembranosus muscle ( $m$. semimembranosus) from Limousine cattle (live weight around $400-450 \mathrm{~kg}$, organic breeding system) were used in this study. After $48 \mathrm{~h}$ of slaughter, semimembranosus muscles were marinated in acid whey for $24 \mathrm{~h}$ at $4{ }^{\circ} \mathrm{C}$. Each variant (about $6 \mathrm{~kg}$ beef per variant) was immersed in $1.5 \mathrm{~L}$ of acid whey. Then, the meat was salted with sea salt at $3 \%$ on the meat weight and placed to rest for $24 \mathrm{~h}$ at $4{ }^{\circ} \mathrm{C}$. After salting, $1 \%$ of glucose was added to the meat. Products were subjected to $31 \mathrm{~d}$ of ripening at $16{ }^{\circ} \mathrm{C}$ and relative humidity $75-85 \%$. After ripening, the beef was cold-smoked for $1 \mathrm{~h}$ at $26{ }^{\circ} \mathrm{C}$ with oak-alder wood chips and then vacuum packaged and stored at $4{ }^{\circ} \mathrm{C}$. Products were tested after one month of cold storage. The experiments were performed in triplicate.

\section{Extraction and identification of peptides}

Peptides were isolated according to Mora et al. (2010). After concentration in the evaporator, peptides were dissolved in $2 \mathrm{~mL}$ of $0.01 \mathrm{M} \mathrm{HCL}$ and subjected to further chromatographic analysis. The peptide mix- 
ture was separated using nanoACQUITY (Waters) liquid chromatography instruments and Orbitrap Velos Mass Spectrometer. The peptide mixture was applied to a RP18 column using a gradient of acetonitrile $(0-35 \% \mathrm{AcN})$ for over $180 \mathrm{~min}$, in the presence of $0.05 \%$ formic acid

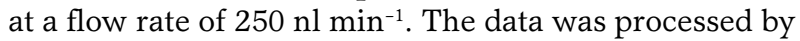
Mascot Distiller then Mascot Search and later compared to the Uniprot database. The search parameters for precursor ions and mass tolerance products were $10 \mathrm{ppm}$ and 0.1. Da. The study was repeated three times.

\section{Anti-health properties}

The toxic and allergenic properties of peptide sequences were determined using an in silico method. The peptide sequences were assessed for potential toxicity using ToxinPred web server (Gupta et al., 2013). The prediction method was based on the support vector machine (SVM) and the SVM threshold value of 0.0 was applied for toxicity prediction (Lafarga et al., 2015; Kęska and Stadnik, 2016a). The above-mentioned peptides were also assessed for potential allergenic properties using tools available at the BIOPEP-UWM database (http://www.uwm.edu.pl/biochemia/index.php/pl/ biopep) (Minkiewicz et al., 2008). A profile for epitopes was created, which shows the potential presence and location of epitope fragments in a protein sequence. The frequency of the occurrence of allergenic fragments in a protein sequence ( $A$ parameter) was also determined according to the equation: $A=\mathrm{a} \mathrm{N}^{-1}$; where $\mathrm{a}$ is the number of fragments defined as epitope and $\mathrm{N}$ is the number of amino acid residues of protein. Parameter $A$ determined for epitopes was marked as $A_{E P}$ in this study for a better interpretation of results.

\section{Health-promoting properties}

The chromatographic analysis was used to assess potential of health-promoting properties of ripening beef meat products. The overall bioactivity of the obtained peptide sequences was determined using the tools available on the server Peptide Ranker (http://bioware.ucd. ie / compass/biowareweb/Server_pages/peptideranker. php). The profile of potential biological activity of peptides and frequency of bioactive fragments occurrence in a protein sequence (parameter $A$ ) was determined using the tools available at the BIOPEP-UWM database. Parameter $A$ is available in tab "Calculations" and is estimated according to a procedure similar to described previously (i.e. $A=\mathrm{a} \mathrm{N}^{-1}$ ), wherein a is the number of fragments with a given activity in a protein sequence.

\section{Results and Discussion}

\section{Profiling of ripening and refrigeration storage products}

A typical LC-MS/MS base peak chromatogram because of chromatographic analyses was shown in Figure 1. After three independent repeats, 1,464 peptides were identified. Among these peptides, 452 peptide sequences, whose presence was confirmed in each repetition, were selected for further analysis. The potential bioactivity index was determined for each identified peptide, based on bioinformatic tools (PeptideRanker). PeptideRanker is a server for predicting bioactive peptides based on the novel N-to-1 neural network, which allows an assessment to confirm if the examined sequence is biologically active. The numerical indicator ranged from 0 (no activity) to 1 (maximum bioactivity). As an example, Table 1 provides $62(14 \%)$ peptides for which the value of the bioactivity index was greater than 0.5 .

Selected peptides had from 7 to 21 amino acids in the sequence and showed bioactivity from 0.5 to 0.97, according to the PeptideRanker score. Of these, the highest potential activity was determined for the octapeptide FPMNPPKF and the nonapeptide FPM-

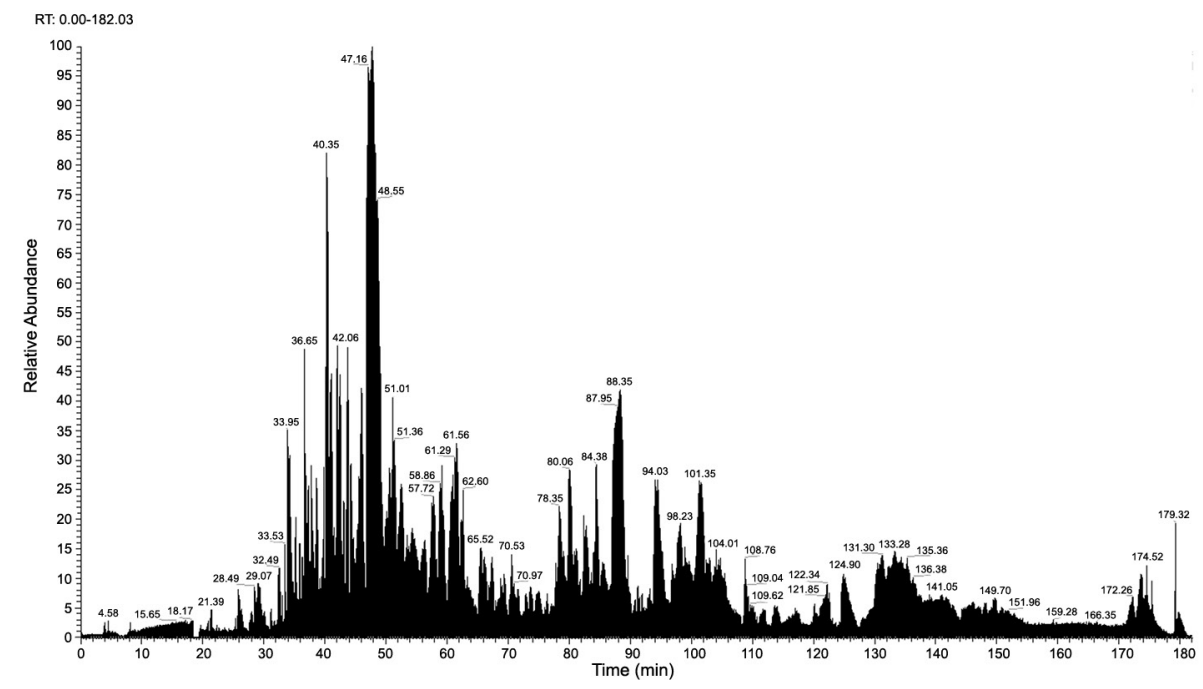

Figure 1 - Representative base peak chromatogram spectra ethanol-soluble fragments from ripening beef with acid whey. 
Table 1- Peptides with potential high biological activity - an in silico study.

\begin{tabular}{|c|c|c|c|c|c|c|c|}
\hline No & Peptide & Mass [Da] & Peptide ranker & No & Peptide & Mass [Da] & Peptide ranker \\
\hline 1 & VPPLPLI & 747.48 & 0.73 & 32 & DQVFPMNPPKFD & 1433.66 & 0.59 \\
\hline 2 & VPPLPLL & 747.48 & 0.84 & 33 & GGPAPEAITDKIF & 1442.74 & 0.63 \\
\hline 3 & TPIPWLS & 812.44 & 0.67 & 34 & PVVPPLIPPKIPEG & 1451.87 & 0.63 \\
\hline 4 & LKLAGFGL & 817.51 & 0.55 & 35 & APPIQSPLPVIPHQ & 1492.84 & 0.53 \\
\hline 5 & DRHGGFKP & 914.46 & 0.60 & 36 & GSGLVKAGFAGDDAPR & 1516.76 & 0.58 \\
\hline 6 & FPMNPPKF & 976.48 & 0.97 & 37 & DDHFLFDKPVSPL & 1528.76 & 0.75 \\
\hline 7 & HAKHPSDFG & 994.46 & 0.51 & 38 & DDHFLFDKPVSPI & 1528.76 & 0.60 \\
\hline 8 & VPIPTMPIR & 1022.59 & 0.68 & 39 & MPKFDLGPLLSEPL & 1555.83 & 0.68 \\
\hline 9 & GNPELILPVP & 1047.60 & 0.55 & 40 & FPMNPPKFDKIED & 1576.76 & 0.55 \\
\hline 10 & SDGTLLQPLK & 1070.60 & 0.58 & 41 & GSGLVKAGFAGDDAPRA & 1587.80 & 0.61 \\
\hline 11 & GEAAPYLRKS & 1090.58 & 0.50 & 42 & FAGDDAPRAVFPSIVG & 1617.82 & 0.64 \\
\hline 12 & FPMNPPKFD & 1091.51 & 0.87 & 43 & DFGADAQAAMSKALEL & 1636.78 & 0.52 \\
\hline 13 & PVVPPFLQP & 1091.63 & 0.56 & 44 & IDDHFLFDKPVSPI & 1641.84 & 0.55 \\
\hline 14 & AGNPELILPVP & 1118.63 & 0.55 & 45 & IDDHFLFDKPVSPL & 1641.84 & 0.71 \\
\hline 15 & VGVNGFGRIGR & 1130.63 & 0.53 & 46 & PTIPEEEAKKLFPKG & 1682.92 & 0.53 \\
\hline 16 & TAPKGKVGGRW & 1155.65 & 0.57 & 47 & LIDDHFLFDKPVSPI & 1754.92 & 0.50 \\
\hline 17 & AAQYKVLGFHG & 1189.62 & 0.54 & 48 & LIDDHFLFDKPVSPL & 1754.92 & 0.65 \\
\hline 18 & AGNPELILPVPA & 1189.67 & 0.51 & 49 & GRPTPKSSWEFDGKAK & 1789.91 & 0.58 \\
\hline 19 & GTAPKGKVGGRW & 1212.67 & 0.70 & 50 & GHPETLEKFDKFKHL & 1824.95 & 0.63 \\
\hline 20 & GLSDGEWQIVL & 1215.61 & 0.51 & 51 & GAPSFPLGSPLSSPVFPRAG & 1940.02 & 0.89 \\
\hline 21 & GLSDGEWQLVL & 1215.61 & 0.60 & 52 & STGAAKAVGKVIPELNGKLT & 1953.13 & 0.56 \\
\hline 22 & MSADAMLKALLG & 1219.63 & 0.54 & 53 & HPSDFGADAQAAMSKALEL & 1957.92 & 0.59 \\
\hline 23 & DAGELDFSGLLK & 1263.63 & 0.67 & 54 & SQPDVDGFLVGGASLKPEF & 1961.97 & 0.85 \\
\hline 24 & PEPAKSAPAPKKG & 1276.71 & 0.54 & 55 & AIPEGQFIDSKKASEKLL & 1973.08 & 0.60 \\
\hline 25 & AGTAPKGKVGGRW & 1283.71 & 0.73 & 56 & STGAAKAVGKVIPELNGKLTG & 2010.15 & 0.67 \\
\hline 26 & TAPKGKVGGRWK & 1283.75 & 0.52 & 57 & ASHLPSDFTPAVHASLDKF & 2039.01 & 0.56 \\
\hline 27 & DQVFPMNPPKF & 1318.64 & 0.83 & 58 & LDDLPGALSELSDLHAHKL & 2043.06 & 0.55 \\
\hline 28 & AVGKVIPELNGKL & 1336.81 & 0.52 & 59 & FTGHPETLEKFDKFKHL & 2073.07 & 0.50 \\
\hline 29 & GTAPKGKVGGRWK & 1340.77 & 0.64 & 60 & ASHLPSDFTPAVHASLDKFL & 2152.09 & 0.68 \\
\hline 30 & IDDHFLFDKPV & 1344.67 & 0.62 & 61 & FTGHPETLEKFDKFKHLK & 2201.16 & 0.50 \\
\hline 31 & APPIQSPLPVIPH & 1364.78 & 0.61 & 62 & EQQQLIDDHFLFDKPVSPL & 2268.14 & 0.52 \\
\hline
\end{tabular}

NPPKFD (bioactivity score 0.97 and 0.87 , respectively). These sequences were assigned to the myosin chain, as a source of origin (Uniprot ID: Q9BE40 and Q9BE41). The above-mentioned peptides were characterized by a particularly high potential activity for inhibiting the action of enzymes: angiotensin-converting enzyme ACE-I inhibitor $(A=0.8750$ and $A=0.7778$, respectively) and dipeptidyl peptidase IV (DPP IV) inhibitor ( $A=0.8750$ and $A=0.7778$, respectively). In turn, the GAPSFPLGSPLSSPVFPRAG bioactivity (PeptideRanker score $=0.89$ ), a peptide derived from desmin (Uniprot ID: O62654) showed potential bioactivity as ACE-I and DPP IV inhibitor ( $A=0.7000$ for both). Triosephosphate isomerase (Uniprot ID: Q5E956) was also a source of high biological activity (PeptideRanker score $=0.85$ ) as ACE-I inhibitor $(A=0.5789)$ and DPP IV inhibitor $(A$ $=0.4211$ ).

Bioactive peptides derived from food may be multifunctional and exhibit two or more different biological activities. The active dipeptides or tripeptides, such as enzyme inhibitors or antioxidants, showed the strongest impact on the physiological function in human body (Erdmann et al., 2008). The high bioactivity potential de- termined for the FPMNPPKF peptide is due to the presence of shorter fragments with high biological effects in its sequence (for example, shorter fragments in the peptide structure may act either as ACE-I inhibitors - FP, MNPPK, MNP, NPP, and PPK or DPP IV inhibitors - PP, $\mathrm{FP}, \mathrm{NP}, \mathrm{KF}, \mathrm{MN}, \mathrm{PK}$, and PM).

\section{In silico analysis of potential anti-health properties of the identified peptides}

The potential of anti-health properties for each peptide sequence was evaluated, inter alia by their toxicity, based on an in silico approach. For this purpose, a tool available in ToxinPred webserver was used. This solution only allows the analysis of peptides that are not longer than 30 amino acids in length and therefore data on the possible toxic activities of the three identified peptides (ISDAIIHVLHAKHPSDFGADAQAAMSKALEL, IYKKLRDKETPSGFTLDDVIQTGVDNPGHPF, and EIYKKLRDKETPSGFTLDDVIQTGVDNPGHPF) are not available. The remaining sequences of the peptides did not show toxic properties.

Meat and meat products, which contribute to the nutritional and functional values of the daily human 
diet, can also be the cause of diseases to populations, including allergies. Food allergies are the major public health problem worldwide. Doctors report that such incidences are increasing steadily, but so far, a universal method to fight them has not been developed. Epidemiological data report that food allergies affect $8 \%$ of children and $5 \%$ of adults (van Hengel, 2007; Sicherer and Sampson, 2014). Milk proteins are some of the most dangerous food allergens. The use of acid whey in preparation of ripening beef is likely to affect allergenic properties of the product. Therefore, in order to assess whether peptides released from ripening beef can be used as functional food ingredients for human consumption, their allergenicity was determined. The potential of peptides to induce food allergies was evaluated, based on the information in the BIOPEP-UWM database available at "Allergenic proteins and their epitopes". Within the sequences of analyzed peptides, epitopes (i.e., a part of a macromolecule recognized by the immune system), responsible for causing the allergic response of organisms, were located. The search for local identity sequence using epitopes as a sequence of queries is the simplest possible strategy for bioinformatics to find new allergens. Among all peptides, ten sequences $(2 \%)$ have potential allergenic properties (Table 2).

All potentially allergenic peptide sequences had myoglobin as the source of origin (Figure 2). These results correspond with reports of other authors (Fuentes et al., 2004; Fiocchi et al., 2005).

Table 2 - Profile of epitope occurrence in peptide sequences of ripening beef meat product ${ }^{1}$.

\begin{tabular}{lccc}
\hline No & Peptide sequences & Location & $A_{E P}$ parameter for epitope \\
\hline 1 & IRLFTGHPETLEKFDK & $11-16$ & 0.0182 \\
2 & TGHPETLEKFDKFK & $7-12$ & 0.0625 \\
3 & TGHPETLEKFDKFKH & $7-12$ & 0.0588 \\
4 & FTGHPETLEKFDKFK & $8-13$ & 0.0667 \\
5 & GHPETLEKFDKFKHL & $6-11$ & 0.0667 \\
6 & TGHPETLEKFDKFKHL & $7-12$ & 0.0556 \\
7 & FTGHPETLEKFDKFKH & $8-13$ & 0.0625 \\
8 & FTGHPETLEKFDKFKHL & $8-13$ & 0.0526 \\
9 & FTGHPETLEKFDKFKHLK & $8-13$ & 0.0500 \\
10 & IRLFTGHPETLEKFDKFKHL & $11-16$ & 0.0417 \\
\hline${ }^{1}$ All sequences were designated as the fragments of bovine myoglobin (Uniprot
\end{tabular}
ID: P02192).

\begin{tabular}{|c|c|c|c|c|}
\hline 10 & 20 & 30 & 40 & 50 \\
\hline GLSDGEWQL & VLNAWGKVEA & DVAGHGQEVL & IRLFTGHPET & LEKFDKFKHL \\
\hline 60 & 70 & 80 & 90 & 100 \\
\hline EAEMKASE & DLKKHGNTVL & TALGGILKKK & GHHEAEVKHL & AESHANKHKI \\
\hline 110 & 120 & 130 & 140 & 150 \\
\hline PVKYLEFISD & AllHVLHAKH & $\begin{array}{r}\text { PSDFGADAQA } \\
\text { GFHG }\end{array}$ & AMSKALELFR & NDMAAQYKVL \\
\hline
\end{tabular}

Figure 2 - Bovine myoglobin sequences (Uniprot ID:P02192). Identified fragments with epitopes are listed in bold. The potentially allergenic sequence is underlined.
The occurrence frequency of epitopes in the protein sequence (indicated as $A_{E P}$ parameter) was determined. $A_{E P}$ was understood as the ratio of the number of fragments defined as epitopes to the number of amino acid residues in the protein sequence. For the identification of proteins as allergens that are able to crossreact with previously known allergens, the WHO recommends the following official bioinformatics criteria: presence of a common fragment containing at least 6-8 amino acid residues or of a fragment containing at least 80 amino acid residues with an identity of at least $35 \%$ (Goodman, 2006; Ivanciuc et al., 2009). All sequences obtained have this fact in common, the six amino acid domain LEKFDK, residues identical to the corresponding fragment of a query peptide sequence, according to the official WHO criteria. It is a linear epitope of the allergen Bos d 5, characteristic of the allergenic bovine (Bos taurus) protein beta-lactoglobulin, gen. var. A (Dziuba et al., 2013; Restani et al., 2009). Beta-lactoglobulins Bos d 5 are thermostable food allergens, which are resistant to proteolytic enzymes and hydrochloric acid. This feature does not allow the processes and action of digestive enzymes to change their allergenicity. All sequences containing epitope LEKFDK are assigned as myoglobin fragment based on processing the Mascot Distiller followed by Mascot Search and in comparison to the Uniprot database. In order to determine whether the application of acid whey can affect the allergenic properties of beef products, the sequences of myoglobin (Uniprot ID: P02192) and beta-lactoglobulin (Uniprot ID: P02754) were compared using the basic local alignment search tool (BLAST; Figure 3) (Goodman et al., 2016). Regions with similar sequence of proteins were not found, except for a single significant adjustment of short segment, which turned out to be the epitope LEKFDK. Thus, identified sequences from bovine meat tissue and the use of acid whey for beef production cannot additionally strengthen allergenicity of the final product. However, in silico methods use a variety of physicochemical properties (mainly amino acids search) of proteins that can be utilized; however, a strong correlation between the structural characteristics and the operation of sensitization has not been confirmed. Using innovative methods for in silico prediction of allergenicity will largely depend on the choice of databases and algorithms to be developed, standardized, and, most importantly, empirically validated (Hayes et al., 2015). Determining the potential allergen is not enough to prove allergenicity of peptides. Further studies based on biochemical and biological tests are needed to confirm the allergy potential.

Experimentally, it was found that the linear sequences of the epitopes in bovine whey proteins are also present in milk of other animals such as goats (Capra hircus), sheep (Ovis aries), and buffalo (Bubalus bubalis) (Table 3). Thus, proteins from milk of these species should be classified as allergens, based on the local sequence identity, which exhibit cross-reactivity with bovine milk protein (Minkiewicz et al., 2011; Restani et 
Table 3 - Epitope structure LEKFDK present in various food proteins ${ }^{1}$.

\begin{tabular}{ll}
\hline $\mathrm{ID}$ of allergenic proteins & \multicolumn{1}{c}{ Name of allergenic protein } \\
\hline 14 & beta-lactoglobulin, gen. var. A, precursor, bovine (Bos taurus), Allergen Bos d 5 \\
77 & beta-lactoglobulin, precursor, sheep (Ovis aries), allergen Ovi a BLG \\
100 & beta-lactoglobulin, goat (Capra hircus), allergen Cap h BLG \\
108 & beta-lactoglobulin, water buffalo (Bubalus bubalis), allergen Bub b BLG \\
\hline
\end{tabular}

1based on information available at "profiles of epitope occurrence in your sequence" offered at BIOPEP-UWM database; ${ }^{2} \mathrm{D}$ in BIOPEP-UWM database.

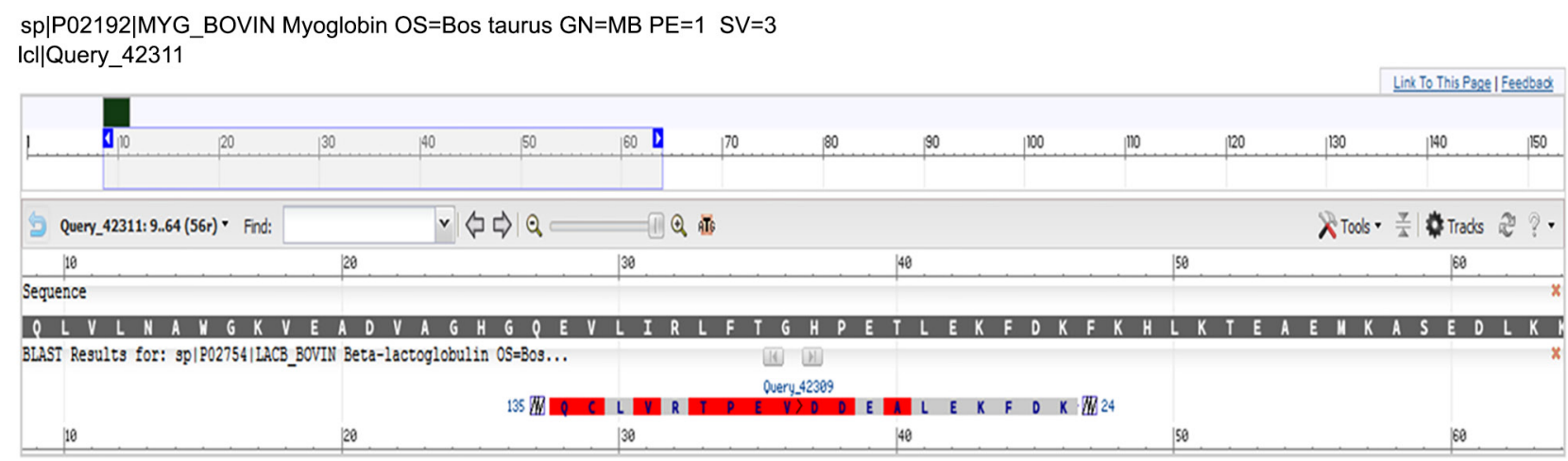

Figure 3 - Graphical results of alignment for myoglobin and beta-lactoglobulin from Bos taurus using Blast tool (identical fragment has been shaded in light gray).

al., 2009). Therefore, possibly, cross-reaction may occur even after the ingestion of ripening beef, due to the presence of myoglobin.

\section{In silico analysis of potential nutritional properties of the identified peptides \\ Biologically active peptides derived from food} sources are short sequences released by the breakdown of protein molecules that exert physiological, hormonelike effects on humans besides the contribution of their nutritional value. Integrity and activity of food ingredients change during food production, which generates various breakdown/transformation products under the influence of biochemical and enzymatic reactions. This also applies to the proteolytic transformation of proteins under different conditions with the influence of endogenous and exogenous environmental factors. Depending on the amino acid sequence, these peptides may exhibit a variety of activities. The ripening of beef products with acid whey after one month of refrigeration storage are a potential source of biopeptides, which shows 17 different activities: dipeptidyl peptidase IV inhibitor (DPP IV inhibitor; 452), angiotensin converting enzyme inhibitor (ACE-I inhibitor; 449), antioxidative (268), stimulating (203), the bacterial permease ligand (82) inhibitor (other than DPP IV inhibitor or ACE-I inhibitor, 82), antithrombotic (62), hypotensive (57) regulating (46) antiamnesic (45); immunomodulating (43) ubiquitin-mediated (28), opioid (16) neuropeptide (6), anticancer (2), anorectic (2) and chemotactic (2) (numbers in parentheses denote the number of peptides with the biological activity). We present peptide sequences (maximum ten) with proper- ties relevant to the proper maintenance of good health and well-being - including cardiovascular effects by regulating the blood pressure or oxidation of stress (Table 4) effects of nervous and immune systems (Table 5), or supporting maintenance of general homeostasis (Table 6).

Regarding the daily diet, the modulation of immune response can occur in the gut associated lymphoid tissue (GALT), which is located within the gastrointestinal track. It plays a very important role, because most antigens enter the human body through the intestinal mucosa. Efficient functioning of the immune system at this level prevents the intestinal barrier and penetration of pathogens into the body (Kuśmierska and Fol, 2014). Therefore, food is a potential source of immunomodulatory compounds that can be used to control immune responses (Santiago-Lopez et al., 2016). The action mechanism of bioactive peptides for controlling and preventing diseases consists of suppressing or stimulating some immune responses. Bovine milk, eggs, mushroom, soybean, and wheat as the source of immunoactive peptides from different food materials were presented in the literature (Hartmann and Meisel, 2007; Agyei and Danquah, 2012). However, to the best of knowledge, information about fermented/ripening meat products as a source of factors affecting the immune system is limited. Kęska and Stadnik (2016b) demonstrated the prospective of pork protein as a potential source of immunomodulators in in silico approach. Moreover, these studies enriched by the results of chromatographic analyses provide insights into the sequence of peptides obtained by protein degradation in vivo in ripening beef product with acid whey, which enable a better assessment of the 
Table 4 - Peptide sequences influencing the cardiovascular system.

\begin{tabular}{|c|c|c|c|}
\hline Activity & Sequences & Protein & A \\
\hline \multirow{10}{*}{ DPP IV inhibitor } & VPPLPLI ${ }^{1}$ & $\mathrm{~N}^{2}$ & 1.1429 \\
\hline & VPPLPLL ${ }^{1}$ & $\mathrm{NI}$ & 1.1429 \\
\hline & VPTVPLP & $\mathrm{NI}$ & 1.0000 \\
\hline & QETVAPGATVGQVLGA & $\mathrm{NI}$ & 0.9375 \\
\hline & PVVPPLIPPKIPEG & Q8MKH6(Troponin T, slow skeletal muscle) & 0.9286 \\
\hline & APPIQSPLPVIPH & $\mathrm{NI}$ & 0.9231 \\
\hline & TEGGATLTVK & Q9BE41 (Myosin-2) & 0.9000 \\
\hline & PVVVPPFLQPE & P02666 (Beta-casein) & 0.9091 \\
\hline & DQVFPMNPPKF & Q9BE40 (Myosin-1) & 0.9091 \\
\hline & APPPPAEVPEVHEEVHE & Q8MKI3 (Troponin T, fast skeletal muscle) & 0.8824 \\
\hline \multirow{10}{*}{ ACE-I inhibitor } & LKLAGFGL & $\mathrm{NI}$ & 0.8750 \\
\hline & FPMNPPKF & Q9BE40 (Myosin-I) & 0.8750 \\
\hline & GSGLVKAGFAGDDAPRAVFPS & Q3ZC07 (Actin, alpha cardiac muscle 1); P68138 (Actin, alpha skeletal muscle) & 0.8571 \\
\hline & AGTAPKGKVGGRW & Q8MKI3 (Troponin T, fast skeletal muscle) & 0.8426 \\
\hline & GSGLVKAGFAGDDAPR & P68138 (Actin, alpha skeletal muscle) & 0.8235 \\
\hline & EKAGAHLKGGAKR & $\mathrm{Nl}$ & 0.8125 \\
\hline & GSGLVKAGFAGDDAPRAVFPSIVG & Q3ZC07 (Actin, alpha cardiac muscle 1); P68138 (Actin, alpha skeletal muscle) & 0.7919 \\
\hline & PVVPPLIPPKIPEG & Q8MKH6 (Troponin T, slow skeletal muscle) & 0.7857 \\
\hline & FPMNPPKFD & Q9BE40 (Myosin-1) & 0.7778 \\
\hline & EKAGAHLKG & P10096(Glyceraldehyde-3-phosphate dehydrogenase) & 0.7778 \\
\hline \multirow{10}{*}{ Antioxidant } & IGAEVYHHLK & Q3ZC09 (Beta-enolase) & 0.5000 \\
\hline & IGAEVYHHLKG & Q3ZC09 (Beta-enolase) & 0.4545 \\
\hline & EKAGAHLKG & P10096 (Glyceraldehyde-3-phosphate dehydrogenase) & 0.4444 \\
\hline & MRIGAEVYHHLK & Q3ZC09 (Beta-enolase) & 0.4167 \\
\hline & IGAEVYHH & Q3ZC09 (Beta-enolase) & 0.3750 \\
\hline & EKAGAHLKGGAK & P10096 (Glyceraldehyde-3-phosphate dehydrogenase) & 0.3330 \\
\hline & MEKAGAHLKGGAK & P10096 (Glyceraldehyde-3-phosphate ehydrogenase) & 0.3077 \\
\hline & MRIGAEVYHH & Q3ZC09 (Beta-enolase) & 0.3000 \\
\hline & KKGHHEA & P02192 (Myoglobin) & 0.2857 \\
\hline & TPIPWLS & Myozenin-1 (Q8SQ24) & 0.2857 \\
\hline \multirow{10}{*}{ Antitrombotic } & NEEIDEMLKEAPGPINF & Q3SZE5 (Myosin regulatory light chain 2, ventricular/cardiac muscle isoform) & 0.1765 \\
\hline & VGPEVEK & Q3TOP6 (Phosphoglycerate kinase 1) & 0.1429 \\
\hline & FPMNPPKF & Q9BE41 (Myosin-2) & 0.1250 \\
\hline & FPMNPPKFD & Q9BE41 (Myosin-2) & 0.1110 \\
\hline & DQVFPMNPPKF & Q9BE41 (Myosin-2) & 0.0909 \\
\hline & GGPEAGKSEQPEN & Q3T149 (Heat shock protein beta-1) & 0.0769 \\
\hline & EDQVFPMNPPKFD & Q9BE41 (Myosin-2) & 0.0769 \\
\hline & TPIPWLSSGEPVD & Q8SQ24 (Myozenin-1) & 0.0769 \\
\hline & PVYPPLIPPKIPEG & Q8MKH6 (Troponin T, slow skeletal muscle) & 0.0714 \\
\hline & DVIQTGVDNPGHPF & Q9XSC6 (Creatine kinase M-type) & 0.0714 \\
\hline \multirow{10}{*}{ Hypotensive } & EKFDKFKH & P02192 (Myoglobin) & 0.2500 \\
\hline & IRLFTGHPETLEKFDKFKHL & P02192 (Myoglobin) & 0.1500 \\
\hline & TGHPETLEKFDKFK & P02192 (Myoglobin) & 0.1429 \\
\hline & FTGHPETLEKFDKF & P02192 (Myoglobin) & 0.1429 \\
\hline & GHPETLEKFDKFKH & P02192 (Myoglobin) & 0.1429 \\
\hline & TGHPETLEKFDKFKH & P02192 (Myoglobin) & 0.1333 \\
\hline & FTGHPETLEKFDKFK & P02192 (Myoglobin) & 0.1333 \\
\hline & GHPETLEKFDKFKHL & P02192 (Myoglobin) & 0.1333 \\
\hline & FTGHPETLEKFDKFKH & P02192 (Myoglobin) & 0.1250 \\
\hline & FPMNPPKF & Q9BE41 (Myosin-2) & 0.1250 \\
\hline
\end{tabular}

IVPPLPLI and VPPLPLL also show activity as ACE-I inhibitor $(A=0.8571)$; inhibitor $(A=0.1429)$. In order to avoid an excessive number of repetitions they were omitted from the table; ${ }^{2} \mathrm{Nl}=$ not identified. 
Table 5 - Peptide sequences influencing the immune and nervous systems.

\begin{tabular}{|c|c|c|c|}
\hline Activity & Sequences & Protein & A \\
\hline \multirow{10}{*}{ Immunomodulating } & LKTEAEMK & P02192 (Myoglobin) & 0.1250 \\
\hline & KKKGHHEAE & P02192 (Myoglobin) & 0.1111 \\
\hline & TEAEMKASEDLK & P02192 (Myoglobin) & 0.0833 \\
\hline & GGILKKKGHHEAE & P02192 (Myoglobin) & 0.0769 \\
\hline & KTEAEMKASEDLK & P02192 (Myoglobin) & 0.0769 \\
\hline & TEAEMKASEDLKK & P02192 (Myoglobin) & 0.0769 \\
\hline & LKTEAEMKASEDLK & P02192 (Myoglobin) & 0.0714 \\
\hline & KTEAEMKASEDLKK & P02192 (Myoglobin) & 0.0714 \\
\hline & FDKFKHLKTEAEMK & P02192 (Myoglobin) & 0.0714 \\
\hline & LKGVIKAKYGKDA & Q3ZC09 (Beta-enolase) & 0.0769 \\
\hline \multirow{10}{*}{ Opioid } & YYPLKSMTEQEQQQLIDDHF & Q9XSC6 (Creatine kinase M-type) & 0.0500 \\
\hline & GAPSFPLGSPLSSPVFPRAG & 062654 (Desmin) & 0.0500 \\
\hline & GKYYPLKSMTEQEQQQLIDDH & Q9XSC6 (Creatine kinase M-type) & 0.0476 \\
\hline & GKYYPLKSMTEQEQQQLIDDHF & Q9XSC6 (Creatine kinase M-type) & 0.0455 \\
\hline & GKYYPLKSMTEQEQQQLIDDHFL & Q9XSC6 (Creatine kinase M-type) & 0.0435 \\
\hline & FKGKYYPLKSMTEQEQQQLIDDH & Q9XSC6 (Creatine kinase M-type) & 0.0435 \\
\hline & KGKYYPLKSMTEQEQQQLIDDHFL & Q9XSC6 (Creatine kinase M-type & 0.417 \\
\hline & GEFKGKYYPLKSMTEQEQQQLIDDH & Q9XSC6 (Creatine kinase M-type) & 0.0400 \\
\hline & FKGKYYPLKSMTEQEQQQLIDDHFL & Q9XSC6 (Creatine kinase M-type) & 0.0400 \\
\hline & TGEFKGKYYPLKSMTEQEQQQLIDDH & Q9XSC6 (Creatine kinase M-type) & 0.0385 \\
\hline \multirow{6}{*}{ Neuropeptide } & GEAAPYLRKS & Q9BE39 (Myosin-7); Q9BE40 (Myosin-1); Q9BE41 (Myosin-2) & 0.1000 \\
\hline & AAPYLRKSEK & Q9BE39 (Myosin-7); Q9BE40 (Myosin-1); Q9BE41 (Myosin-2) & 0.1000 \\
\hline & SRYLGKGVLK & Q3ZC09 (Beta-enolase) & 0.1000 \\
\hline & RPRHQGVMVGMGQKD & P60712 (Actin) & 0.0667 \\
\hline & VADKAAYLQGLNSADLLK & Q9BE40 (Myosin-1) & 0.0556 \\
\hline & LAESHANKHKIPVKYLEF & P02192 (Myoglobin) & 0.0556 \\
\hline \multirow{10}{*}{ Regulating and antiamnestic ${ }^{2}$} & NEEIDEMIKEAPGPINF & $\mathrm{N}^{1}$ & 0.1765 \\
\hline & NEEIDEMLKEAPGPINF & $\begin{array}{l}\text { Q3SZE5 (Myosin regulatory light chain 2, ventricular/cardiac muscle } \\
\text { isoform) }\end{array}$ & 0.1765 \\
\hline & VGPEVEK & Q3TOP6 (Phosphoglycerate kinase1) & 0.1429 \\
\hline & GVDNPGHP & Q9XSC6 (Creatine kinase M-type) & 0.1250 \\
\hline & GGPEAGKSEQPEN & Q3T149 (Heat shock protein beta-1) & 0.0769 \\
\hline & GGPAPEAITDKIFQ & Q08DP0 (Phosphoglucomutase-1) & 0.0714 \\
\hline & DVIQTGVDNPGHPF & (Creatine kinase M-type) & 0.0714 \\
\hline & QETVAPGATVGQVLGA & $\mathrm{NI}$ & 0.0625 \\
\hline & MPKFDLGPLLSEPL & Q8SQ24 (Myozenin-1) & 0.0714 \\
\hline & TKQEYDEAGPSIVHR & P68138 (Actin, alpha skeletal muscle) & 0.0667 \\
\hline
\end{tabular}

${ }^{1} \mathrm{NI}=$ not identified; ${ }^{2} \mathrm{VPTVPLP}$ was determined as strong antiamnestic peptide $(A=0.1429)$.

biological potential of bovine proteins. The results of the analyses are shown in Table 5. The role of myoglobin as a good source of immunomodulatory peptides was also emphasized.

Opioid peptides act as opioid-like hormones by interacting with specific receptors in the nervous, endocrine, and immune systems (Martínez-Alvarez, 2013). Opioid peptides are small molecules, which are synthesized in vivo and may function as hormones and neurotransmitters. Typical opioid peptides are endorphin, enkephalin, and prodynorphin that can be produced by the human body. As noted by Lafarga and Hayes (2014), most studies on the production of meat-based opioid peptides are based on blood hydrolysates (hemorphins). However, there are no reports on the generation of opioid peptides from other food-based meat-origin proteins.
Thus, the results presented in this study contribute to this knowledge by addressing the missing gap in this area and highlighting the role of creatine kinase M-type as the best source of opioid peptides (Table 5).

\section{Conclusion}

The peptidomics and bioinformatics approaches used in this study indicated the peptide sequences obtained from beef product with acid whey have high potential for modulating various functions of the human system, especially as an ACE-I inhibitor and DPP IV inhibitor or as an antioxidant agent. In addition, all peptide fragments exhibited more than one biological activity due to the presence of shorter fragments in the sequences. These fragments are likely to be released 
Table 6 - Peptide sequences with other activities.

\begin{tabular}{|c|c|c|c|}
\hline Activity & Sequences & Protein & A \\
\hline \multirow{10}{*}{ Stimulating } & KKEEEELVALKERIEK & Q8MKI3 (Troponin T, fast skeletal muscle) & 0.3750 \\
\hline & ISDAIIHVL & P02192 (Myoglobin-2) & 0.2220 \\
\hline & AEEEYPDLSKHNNH & Q9XSC6 (Creatine kinase M-type) & 0.2143 \\
\hline & EVHTKIISE & Q9BE40 (Myosin-1) & 0.2000 \\
\hline & ISDAIIHVLH & P02192 (Myoglobin) & 0.2000 \\
\hline & HIITHGEEKD & Q3SZE5 (Myosin regulatory light chain 2, ventricular/cardiac muscle isoform) & 0.2000 \\
\hline & REVHTKIISE & Q9BE40 (Myosin-1) & 0.2000 \\
\hline & GNPELILPVP & Q3ZC09 (Beta-enolase) & 0.2000 \\
\hline & PTIPEEEAKKLFPKG & 077834 (Peroxiredoxin-6) & 0.2000 \\
\hline & KAEEEYPDLSKHNNH & Q9XSC6 (Creatine kinase M-type) & 0.2000 \\
\hline \multirow{10}{*}{$\begin{array}{l}\text { Bacterial permease } \\
\text { ligand }\end{array}$} & KKGHHEA & P02192 (Myoglobin) & 0.4429 \\
\hline & KKKGHHE & P02192 (Myoglobin) & 0.4286 \\
\hline & KKKGHHEA & P02192 (Myoglobin) & 0.3750 \\
\hline & KKKGHHEAE & P02192 (Myoglobin) & 0.3333 \\
\hline & NILKKKGHHE & $\mathrm{NI}^{1}$ & 0.3000 \\
\hline & GGILKKKGHHE & P02192 (Myoglobin) & 0.2727 \\
\hline & NILKKKGHHEA & $\mathrm{NI}$ & 0.2727 \\
\hline & NILKKKGHHEAE & $\mathrm{NI}$ & 0.2500 \\
\hline & GGILKKKGHHEA & P02192 (Myoglobin) & 0.2500 \\
\hline & GGILKKKGHHEAE & P02192 (Myoglobin) & 0.2308 \\
\hline \multirow{10}{*}{ Inhibitor } & EKFDKFKH & P02192 (Myoglobin) & 0.2500 \\
\hline & GGILKKKGHHEA & P02192 (Myoglobin) & 0.7500 \\
\hline & TGHPETLEKFDKFK & P02192 (Myoglobin) & 0.1429 \\
\hline & FTGHPETLEKFDKF & P02192 (Myoglobin) & 0.1429 \\
\hline & GHPETLEKFDKFKH & P02192 (Myoglobin) & 0.1429 \\
\hline & TGHPETLEKFDKFKH & P02192 (Myoglobin) & 0.1333 \\
\hline & FTGHPETLEKFDKFK & P02192 (Myoglobin) & 0.1333 \\
\hline & GHPETLEKFDKFKHL & P02192 (Myoglobin) & 0.1333 \\
\hline & IRLFTGHPETLEKFDKFKHL & P02192 (Myoglobin) & 0.1500 \\
\hline & MVEMEKKLEKGQSIDDMIPAQK & Q9XSC6 (Creatine kinase M-type) & 0.6364 \\
\hline \multirow{10}{*}{$\begin{array}{l}\text { Activing ubiquitin- } \\
\text { mediated }\end{array}$} & LKLAGFGL & $\mathrm{NI}$ & 0.1250 \\
\hline & QEVQITLAARLG & $\mathrm{NI}$ & 0.0883 \\
\hline & EITALAPSTMKIK & P60712 (Actin) & 0.0769 \\
\hline & DLAGNPELILPVP & Q3ZC09 (Beta-enolase) & 0.0769 \\
\hline & DLAGNPELILPVPA & Q3ZC09 (Beta-enolase) & 0.0714 \\
\hline & LAESHANKHKIPVK & P02192 (Myoglobin) & 0.0714 \\
\hline & FRAAVPSGASTGIYE & Q3ZC09 (Beta-enolase) & 0.0667 \\
\hline & HLAESHANKHKIPVK & P02192 (Myoglobin) & 0.0667 \\
\hline & FRAAVPSGASTGIYEA & Q3ZC09 (Beta-enolase) & 0.0625 \\
\hline & FAGDDAPRAVFPSIVG & $\begin{array}{l}\text { Q3ZC07 (Actin, alpha cardiac muscle 1); } \\
\text { P68138 (Actin, alpha skeletal muscle) }\end{array}$ & 0.0625 \\
\hline \multirow{2}{*}{ Anticancer } & PVVVPPFLQP & P02666 (Beta-casein) & 0.1000 \\
\hline & PVVVPPFLQPE & P02666 (Beta-casein) & 0.0909 \\
\hline \multirow{2}{*}{$\begin{array}{l}\text { Anorectic and } \\
\text { chemotactic }\end{array}$} & NEEIDEMIKEAPGPINF & $\mathrm{NI}$ & 0.0588 \\
\hline & NEEIDEMLKEAPGPINF & Q3SZE5 (Myosin regulatory light chain 2. ventricular/cardiac muscle isoform) & 0.0588 \\
\hline
\end{tabular}

during digestion and absorption in the human gastrointestinal tract as intact fragments (with preserved biological activity) reach a specific site of action in human body. Thus, consumption of dietetic biopeptides from uncured beef fermented with acid whey seems to provide further benefits to the health of humans against lifestyle diseases. Due to the natural protein origin as well as potential properties to enhance health, these products could be used as ingredients in functional foods or nutraceuticals. However, the implementation of effective and cost-effective production strategies for functional meat-based products on an industrial scale primarily requires standardization of analytical methods to determine the satisfactory health-promoting effects of the released peptides, evaluation of sensory properties for consumer acceptance, and, most importantly, well-planned clinical trials to provide 
evidence to support health claims, which must be taken into account during the later stages of research on ripening beef with acid whey.

\section{Acknowledgements}

The study was performed as part of research project No.: HOR-re-027-7-2017 financed by the Minister of Agriculture and Rural Development.

\section{Authors' Contributions}

Conceptualization: Kęska, P.; Wójciak, K.M.; Stadnik, J. Data acquisition: Kęska, P.; Wójciak, K.M.; Stadnik, J. Data analysis: Kęska, P.; Wójciak, K.M.; Stadnik, J. Design of Methodology: Kęska, P.; Wójciak, K.M.; Stadnik, J. Writing and editing: Kęska, P.; Wójciak, K.M.; Stadnik, J.

\section{References}

Agyei, D.; Danquah, M.K. 2012. Rethinking food-derived bioactive peptides for antimicrobial and immunomodulatory activities. Trends in Food Science \& Technology 23: 62-69.

Dziuba, M.; Minkiewicz, P.; Dąbek, P.M. 2013. Peptides, specific proteolysis products, as molecular markers of allergenic proteins - in silico studies. Acta Scientiarum Polonorum Technologia Alimentaria 12: 101-111.

Erdmann, K.; Cheung, B.W.; Schröder, H. 2008. The possible roles of food-derived bioactive peptides in reducing the risk of cardiovascular disease. The Journal of Nutritional Biochemistry 19: 643-654.

Fiocchi, A.; Restani, P.; Bouygue, G.R.; Martelli, A. 2005. Beef allergy in adults and children. Allergy 60: 126-126.

Fuentes, M.; Palacios, R.; Garcés, M.; Caballero, M.L.; Moneo, I. 2004. Isolation and characterization of a heat - resistant beef allergen: myoglobin. Allergy 59: 327-331.

Garcia, S.M.; Díaz, J.M.; Huerta, J.A.; Ruis, P.R.; Ruiperez, F.C.; Zafrilla, P.; Celdran, F.; Tejada, L.; Aleman, J.A. 2017. Dry-cured ham. Its effects on human blood pressure and cardiovascular risk: a clinical study. Journal of Hypertension 35: e257.

Goodman, R.E. 2006. Practical and predictive bioinformatics methods for the identification of potentially cross - reactive protein matches. Molecular Nutrition \& Food Research 50: 655-660.

Goodman, R.E.; Ebisawa, M.; Ferreira, F.; Sampson, H.A.; Ree, R.; Vieths, S.; Baumert, J.L.; Bohle, B.; Lalithambika, S.; Wise, J.; Taylor, S.L. 2016. AllergenOnline: a peer - reviewed, curated allergen database to assess novel food proteins for potential crossreactivity. Molecular Nutrition \& Food Research 60: 1183-1198.

Gupta, S.; Kapoor, P.; Chaudhary, K.; Gautam, A.; Kumar, R.; Raghava, G.P. 2013. Open Source Drug Discovery Consortium. In silico approach for predicting toxicity of peptides and proteins. PLoS One 8: e73957.

Ha, E.; Zemel, M.B. 2003. Functional properties of whey, whey components, and essential amino acids: mechanisms underlying health benefits for active people. The Journal of Nutritional Biochemistry 14: 251-258.
Hartmann, R.; Meisel, H. 2007. Food-derived peptides with biological activity: from research to food applications. Current Opinion in Biotechnology 18: 163-169.

Hayes, M.; Rougé, P.; Barre, A.; Herouet-Guicheney, C.; Roggen, E.L. 2015. In silico tools for exploring potential human allergy to proteins. Drug Discovery Today: Disease Models 17: 3-11.

Ivanciuc, O.; Garcia, T.; Torres, M.; Schein, C.H.; Braun, W. 2009. Characteristic motifs for families of allergenic proteins. Molecular Immunology 46: 559-568.

Kęska, P.; Stadnik, J. 2016a. Porcine myofibrillar proteins as potential precursors of bioactive peptides - an in silico study. Food \& Function 7: 2878-2885.

Kęska, P.; Stadnik, J. 2016b. In silico methods to identify meatderived immunomodulatory peptides. p. 106-113. In: Panfil, M., ed. The development of Young Scientists in Poland. Young Scientists Publisher, Poznań, Poland. (Food and Nutrition. Monographs) (in Polish).

Kuśmierska, A.; Fol, M. 2014. Immunomodulatory and therapeutic properties of probiotic microorganisms. Problems of Hygiene and Epidemiology 95: 529-540 (in Polish, with abstract in English).

Lafarga, T.; Hayes, M. 2014. Bioactive peptides from meat muscle and by-products: generation, functionality and application as functional ingredients. Meat Science 98: 227-239.

Lafarga, T.; O'Connor, P.; Hayes, M. 2015. In silico methods to identify meat-derived prolyl endopeptidase inhibitors. Food Chemistry 175: 337-343.

Lasik, A.; Pikul, J.; Danków, R.; Cais-Sokolińska, D. 2011. The fermentation dynamics of sheep milk with increased proportion of whey proteins. Acta Scientiarum Polonorum Technologia Alimentaria 10: 155-163.

Le Maux, S.; Nongonierma, A.B.; Lardeux, C.; FitzGerald, R.J. 2018. Impact of enzyme inactivation conditions during the generation of whey protein hydrolysates on their physicochemical and bioactive properties. International Journal of Food Science \& Technology 53: 219-227.

Martínez-Alvarez, O. 2013. Hormone-like peptides obtained by marine-protein hydrolysis and their bioactivities. p. 351-367. In: Se-Kwon, K., ed. Marine proteins and peptides: biological activities and applications. Wiley-Blackwell, New York, NY, USA.

Martínez-Sánchez, S.M.; Minguela, A.; Prieto-Merino, D.; ZafrillaRentero, M.P.; Abellán-Alemán, J.; Montoro-García, S. 2017. The effect of regular intake of dry-cured ham rich in bioactive peptides on inflammation, platelet and monocyte activation markers in humans. Nutrients 9: 321.

Minkiewicz, P.; Dziuba, J.; Gładkowska-Balewicz, I. 2011. Update of the list of allergenic proteins from milk, based on local amino acid sequence identity with known epitopes from bovine milk proteins-a short report. Polish Journal of Food and Nutrition Sciences 61: 153-158.

Minkiewicz, P.; Dziuba, J.; Iwaniak, A.; Dziuba, M.; Darewicz, M. 2008. BIOPEP database and other programs for processing bioactive peptide sequences. Journal of AOAC International 91: 965-980.

Montoro-García, S.; Zafrilla-Rentero, M.P.; Celdrán-de Haro, F.M.; Piñero-de Armas, J.J.; Toldrá, F.; Tejada-Portero, L.; AbellánAlemán, J. 2017. Effects of dry-cured ham rich in bioactive peptides on cardiovascular health: a randomized controlled trial. Journal of Functional Foods 38: 160-167. 
Mora, L.; Sentandreu, M.A.; Toldrá, F. 2010. Identification of small troponin $\mathrm{T}$ peptides generated in dry-cured ham. Food Chemistry 123: 691-697.

Pihlanto-Leppälä, A. 2000. Bioactive peptides derived from bovine whey proteins: opioid and ACE-inhibitory peptides. Trends in Food Science \& Technology 11: 347-356.

Restani, P.; Ballabio, C.; Di Lorenzo, C.; Tripodi, S.; Fiocchi, A. 2009. Molecular aspects of milk allergens and their role in clinical events. Analytical and Bioanalytical Chemistry 395: 47-56.

Santiago-López, L.; Hernández-Mendoza, A.; Vallejo-Cordoba, B.; Mata-Haro, V.; González-Córdova, A.F. 2016. Food-derived immunomodulatory peptides. Journal of the Science of Food and Agriculture 96: 3631-3641.

Sicherer, S.H.; Sampson, H.A. 2014. Food allergy: epidemiology, pathogenesis, diagnosis, and treatment. Journal of Allergy and Clinical Immunology 133: 291-307.

Tavares, T.G.; Malcata, F.X. 2013. Whey proteins as source of bioactive peptides against hypertension. p. 75- 114. In: Hernández-Ledesma, B.; Hsieh, C.C., eds. Bioactive food peptides in health and disease. InTech, Rijeka, Croatia.
Wójciak, K.M.; Dolatowski, Z.J. 2015. Effect of acid whey on nitrosylmyoglobin concentration in uncured fermented sausage. LWT-Food Science and Technology 64: 713-719.

Wójciak, K.M.; Dolatowski, Z.J.; Kołożyn-Krajewska, D. 2015. Use of acid whey and probiotic strain to improve microbiological quality and sensory acceptance of organic fermented sausage. Journal of Food Processing and Preservation 39: 539-547.

Wójciak, K.M.; Solska, E. 2016. Evolution of free amino acids, biogenic amines and $\mathrm{N}$-nitrosamines throughout ageing in organic fermented beef. Acta Scientiarum Polonorum Technologia Alimentaria 15: 191-200.

van Hengel, A.J. 2007. Food allergen detection methods and the challenge to protect food-allergic consumers. Analytical and Bioanalytical Chemistry 389: 111-118.

Zhou, L.M.; Yang, J.; Zhang, Z.; Tong, X.; Xu, J.Y.; Wan, Z.; Qin, L.Q. 2017. Chronic effects of intact whey protein on the blood pressure in spontaneously hypertensive rats. Current Topics in Nutraceutical Research 15: 39-44. 